\title{
Integrated assessment of $\mathrm{CO}_{2}$ reduction technologies in China's cement industry
}

\author{
Yufei Wang a,d, Samuel Höller ${ }^{\mathrm{b}}$, Peter Viebahn ${ }^{\mathrm{c}}$, Zhengping Hao ${ }^{\mathrm{a}, *}$ \\ a Research Center for Eco-Environmental Sciences, Chinese Academy of Sciences, 100085 Beijing, China \\ ${ }^{\mathrm{b}}$ Wuppertal Institute for Climate, Environment and Energy, Neue Promenade 6, 10178 Berlin, Germany \\ c Wuppertal Institute for Climate, Environment and Energy, Doppersberg 19, 42103 Wuppertal, Germany \\ d School of Public Policy and Management, Tsinghua University, 100084 Beijing, China
}

\section{A R T I C L E I N F O}

\section{Article history:}

Received 23 April 2013

Received in revised form

22 September 2013

Accepted 3 October 2013

\section{Keywords:}

China

Cement sector

Reduction potentials

$\mathrm{CO}_{2}$ avoidance cost

\begin{abstract}
A B S T R A C T
The main objective of this article is to evaluate $\mathrm{CO}_{2}$ mitigation potential and to calculate costs avoided by the use of different $\mathrm{CO}_{2}$ mitigation technologies in China's cement sector, namely energy efficiency improvements, use of alternative fuels, clinker substitution and carbon capture and storage (CCS). Three scenarios are designed based on the projection of cement output and technology development over the next 40 years (2010-2050). 2.5, 4.7 and $4.3 \mathrm{Gt}$ tonnes of $\mathrm{CO}_{2}$ will be saved totally in basic scenario and two low carbon scenarios up to 2050. By comparing these technologies along the scenarios, it can be concluded that $\mathrm{CO}_{2}$ emissions can mainly be reduced by energy efficiency improvements and use of alternative fuels. Clinker substitution, which reduces the clinker-to-cement ratio as well as energy intensity, results in significant cost advantages. CCS, including post-combustion capture and oxy-fuel combustion capture, could play an important role in the capture of $\mathrm{CO}_{2}$ in the cement industry, and is expected to be in commercial use by 2030 .
\end{abstract}

Crown Copyright $\odot 2013$ Published by Elsevier Ltd. All rights reserved.

\section{Introduction}

Cement production is an energy-intensive manufacturing process that raises considerable concern at both global and local levels and can produce around $5 \%$ of global anthropogenic $\mathrm{CO}_{2}$ emissions (OECD/IEA and WBCSD, 2009). In the decades ahead, demand for cement will continue to increase, primarily to satisfy demand from developing countries, above all China. Output increased from 209.7 to 1868 million tonnes of cement between 1990 and 2010 in China, and now represents over half of the world's total cement production (2011a). The stress placed on the climate highlights the necessity to mitigate $\mathrm{CO}_{2}$ emissions and to introduce suitable mitigation technologies to the cement sector.

Compared with various developed countries or regions, China has great potential to improve its energy efficiency and considerable efforts have been made by the Chinese government in recent decades. For example, during its 11th Five-Year Plan for National Economic and Social Development (11th FYP, 2006-2010) a total reduction in energy intensity of $24.6 \%$ (2011b) was achieved, from $3.78 \mathrm{GJ} / \mathrm{t}$ cement ( $1 \mathrm{kgce}$ can produce $29.3 \mathrm{MJ}$ ) in the reference year 2005 (Quantitative Economics and Audit Society of China, 2011 ) to $2.86 \mathrm{GJ} / \mathrm{t}$ cement in 2010 . The positive attitude of the

\footnotetext{
* Corresponding author. Tel.: +8610 62923564; fax: +861062923564.

E-mail address: zpinghao@rcees.ac.cn (Z. Hao).
}

Chinese government and enterprises alike suggest that further $\mathrm{CO}_{2}$ mitigation technologies will be applied.

The objective of our article is to assess these technologies by evaluating their $\mathrm{CO}_{2}$ mitigation potential and comparing their $\mathrm{CO}_{2}$ avoidance costs. Many studies have been conducted on $\mathrm{CO}_{2}$ mitigation potential and cost assessments in the cement sector. Some of these studies focus on the application of technology at the global level, such as the research conducted by the International Energy Agency (IEA) (OECD/IEA and WBCSD, 2009) and the World Wide Fund for Nature (WWF, 2008). Others such as the European Union (EU) and the United States of America (USA) (CSI/ECRA, 2008; Moya et al., 2011; Pardo et al., 2011) address the regional level. China's cement industry is also the subject of concern because of its large contribution to $\mathrm{CO}_{2}$ emissions ( $\mathrm{Gu}$ et al., 2012; Ke et al., 2012; Lei et al., 2011; Murray and Price, 2008; Price et al., 2009; Shi et al., 2012; Tsinghua University of China, 2008; Xu et al., 2012; Zeng, 2008, 2011). Most of these studies focus on energy efficiency improvements. However, there has been little systematic assessment of different $\mathrm{CO}_{2}$ mitigation technologies, especially from an environmental and economic perspective.

In this paper, basic information on the cement production process is first introduced, providing background for an assessment of $\mathrm{CO}_{2}$ mitigation potential and avoidance costs of those technologies in Section 2. A description of $\mathrm{CO}_{2}$ mitigation measures and technologies, such as their current state of development and key technology parameters, is given in Section 3. Our assessment 
Table 1

Ten selected types of energy efficiency improvement technology (Hasanbeigi et al., 2010b; Price et al., 2009).

\begin{tabular}{|c|c|c|c|}
\hline \multirow[t]{2}{*}{ Technologies } & Economic cost ${ }^{\mathrm{a}}$ & $\mathrm{CO}_{2}$ reduction capacity & $\mathrm{CO}_{2}$ avoided cost $\mathrm{t}^{\mathrm{b}}$ \\
\hline & $\mathrm{RMB}^{\mathrm{c}} / \mathrm{t}$ clinker & $\mathrm{kg} \mathrm{CO} / \mathrm{t}$ clinker & $\mathrm{RMB} / \mathrm{kg} \mathrm{CO} 2$ \\
\hline \multicolumn{4}{|l|}{ (1) Fuel preparation } \\
\hline New efficient coal separators & 0.08 & 0.27 & 0.30 \\
\hline Efficient roller mills for coal grinding & 0.32 & 1.51 & 0.21 \\
\hline \multicolumn{4}{|l|}{ (2) Raw materials preparation } \\
\hline Variable frequency drives in raw mill vent fan & 0.17 & 0.34 & 0.50 \\
\hline Bucket elevators to transport raw meal & 1.56 & 2.54 & 0.61 \\
\hline High-efficiency raw mill vent fans with inverters & 0.23 & 0.37 & 0.62 \\
\hline \multicolumn{4}{|l|}{ (3) Clinker making } \\
\hline Kiln shell heat loss reduction (improved refractories) & 1.71 & 24.60 & 0.07 \\
\hline Energy management and process control systems & 6.84 & 16.61 & 0.41 \\
\hline Adjustable speed drive for kiln fans & 1.54 & 6.27 & 0.25 \\
\hline Optimised heat recovery/upgraded clinker coolers & 1.37 & 8.53 & 0.16 \\
\hline \multicolumn{4}{|l|}{ (4) Finish grinding } \\
\hline High-efficiency cement mill vent fans & 0.06 & 0.13 & 0.46 \\
\hline
\end{tabular}

a Economic cost $=$ capital cost + operational and maintenance cost.

b $\mathrm{CO}_{2}$ avoided cost $=$ cost of implementing energy efficiency measure $/ \mathrm{CO}_{2}$ saved by this measure.

c RMB is the currency of China.

methodologies, such as the scenario design and basic assumptions concerning technologies, are described in Section 4. The results of $\mathrm{CO}_{2}$ reduction capacities and $\mathrm{CO}_{2}$ avoided costs generated by various technologies are given in Section 5. Section 6 provides a comparison and discussion of reduction potential and reduction costs in different scenarios, followed by a sensitivity analysis of material prices and an assessment of the time by when CCS will be commercially deployed, and so on. Finally, an outlook of future research questions will be given and policy implementations on developing China's cement sector will be provided in Section 7.

\section{Cement production process}

A total of 0.9 tonnes of $\mathrm{CO}_{2} / \mathrm{t}$ cement are released in the production of Portland cement (Hasanbeigi et al., 2010b). It is considered the most common type of cement in the world and produced by grinding Portland cement clinker, which is a hydraulic material consisting at least two-thirds by calcium silicates. Firstly, $\mathrm{CO}_{2}$ is emitted due to thermal and electricity energy consumption, involving finish grinding, auxiliary grinding, raw grinding and the clinker burning process, which account for $40 \%, 15 \%, 20 \%$ and $25 \%$ of the total energy consumption, respectively (Madlool et al., 2011). Energy is produced by burning coal, natural gas, biomass, petrocoke, heavy fuel oil, waste fuel or fuel oil. In China, coal is the most important and conventional source of energy. Secondly, approximately 0.527 tonnes of $\mathrm{CO}_{2} / \mathrm{t}$ clinker are emitted in China from calcination during clinker production, where raw materials for production are assumed to be $98.5 \% \mathrm{CaCO}_{3}$ and $1.5 \% \mathrm{MgCO}_{3}(\mathrm{He}, 2009)$. In addition, the clinker-to-cement ratio, ranging from 0.5 to 0.95 , equal to the clinker quality per ton cement, can directly affect $\mathrm{CO}_{2}$ emissions (Madlool et al., 2011). The quantity of $\mathrm{CO}_{2}$ emitted per tonne of cement from the calcination process can be calculated by 0.527 (tonnes of $\mathrm{CO}_{2} / \mathrm{t}$ clinker) multiplied with the clinker-tocement ratio.

Consequently, total $\mathrm{CO}_{2}$ emissions of cement can be calculated using Eq. (1).

Total_ $\mathrm{CO}_{2}$ emissions $=\mathrm{CO}_{2}$ thermal $+\mathrm{CO}_{2}$ electricity

$$
+\mathrm{CO}_{2} \text { calcination }
$$

\section{3. $\mathrm{CO}_{2}$ reduction measures}

Several studies have been conducted on $\mathrm{CO}_{2}$ reduction technologies in the cement sector (Abdelaziz et al., 2011; Mahasenan et al., 2005; US EPA, 2010; WBCSD, 2009; Worrel and Galitsky,
2008). In this article, we argue that there are four main types of $\mathrm{CO}_{2}$ reduction technologies based on the IEA's classification, namely (1) energy efficiency improvements; (2) use of alternative fuels; (3) clinker substitution; and (4) CCS. These technologies will be introduced below, presenting the basic information relevant to our assessment. Other $\mathrm{CO}_{2}$ mitigation technologies or production measures, such as Novacem, Geopolymer cement, are not included in our article considering their development stage.

\subsection{Energy efficiency improvements}

Energy efficiency in cement production can be improved by introducing new technologies, by closing down old plants and constructing new ones. The dry manufacturing process using preheater and precalciner technology (the NSP technique) is currently considered the state of the art in cement production. By the end of the 11th FYP, the proportion of NSP facilities had increased to $81 \%$ of total production (2011a). Ten technologies are identified based on their economic costs and $\mathrm{CO}_{2}$ reduction capacities (see Table 1 ). Details of these technologies can be found in the literature (Hasanbeigi et al., 2010b; Price et al., 2009). The $\mathrm{CO}_{2}$ avoided cost was calculated based on the economic costs and $\mathrm{CO}_{2}$ reduction capacity of these technologies. As the table shows, use of high-efficiency cement mill vent fans incurs the lowest economic cost and kiln shell heat loss reduction saves the largest quantity of $\mathrm{CO}_{2}$ emissions. Kiln shell heat loss reduction has the lowest $\mathrm{CO}_{2}$ avoided cost of these technologies, followed by optimised heat recovery/upgraded clinker coolers.

The energy used in cement production is mainly caused by thermal and electricity consumption. Theoretically, the minimum primary energy consumption for the thermodynamic process is 1.6-1.85 GJ/t clinker (OECD/IEA and WBCSD, 2009). Technically, however, the best energy efficiency currently obtained by preheater kilns with a precalciner ranges from 2.9 to $3.3 \mathrm{GJ} / \mathrm{t}$ clinker (Strategic Energy Technologies Information System, 2011). The thermal intensity of new kilns using the NSP technique can be $3.37 \mathrm{GJ} / \mathrm{t}$ clinker in China (2011a); it may even be much lower for some large-scale enterprises. Electricity consumed in the production of clinker can be $80 \mathrm{kWh} / \mathrm{t}$ clinker or less (WWF, 2008). Additionally, 8-22 kWh/t clinker electricity can be saved by using waste heat recovery (WHR), depending on the waste heat resources and technologies applied (CSI/ECRA, 2008).

\subsection{Use of alternative fuels}

Alternative fuels can replace traditional fuels (mainly coal or petcock) and become integrated into the process of clinker 
production, significantly reducing $\mathrm{CO}_{2}$ emissions. Alternative fuels available for clinker production include pre-treated industrial and municipal solid waste, discarded tyres, waste oil and solvents, plastics, textiles, paper residues and different types of biomass (OECD/IEA and WBCSD, 2009). Use of alternative fuels varies from country to country. For example, in the non-Annex I region, it increases at an annual rate of $0.9 \%$; in developing countries, it increases by $0.5 \% / \mathrm{a}$ (WBCSD, 2009). In this article, we consider only biomass and tyres, assuming they are applied on a much wider scale than other alternative fuel materials in China. The biomass here mainly refers to the agricultural biomass residues, and they are mainly based on crops that locally grown, like rice husk etc. With a common substitution ratio of $20 \%$, tyres are one kind of petroleumbased fuels, which is widely used in U.S. and EU countries.

\subsection{Clinker substitution}

Clinker substitution for blended or limestone cement is another important $\mathrm{CO}_{2}$ reduction measure. Portland cement clinker is ground with blast furnace slag (BFS) from iron and steel plants, fly ash from coal furnaces, volcanic materials and limestone. Due to its greater long-term strength and high resistance to acid and sulphate, blended cement is also produced in China. Additives include BFS, fly ash, cinder, coal gangue, limestone, gypsum, pebble and kiln dust. However, they account for only a small proportion of production; approximately 95\% continues to be produced using Portland cement. The most important indicator is the clinker- to-cement ratio; its reduction can finally lead to a decrease in energy use and $\mathrm{CO}_{2}$ emissions.

\subsection{Carbon capture and storage (CCS)}

Although no pilot or industrial scale trials exist to date, the second greatest potential for CCS to reduce $\mathrm{CO}_{2}$ emissions may be in the cement industry, following the power sector (IEA GHG, 2008). Three main technologies can be used to capture $\mathrm{CO}_{2}$ in the cement sector, namely post-combustion capture, oxy-fuel combustion capture and pre-combustion technology. Post-combustion capture and oxy-fuel combustion capture are considered more promising than pre-combustion. Firstly, $\mathrm{CO}_{2}$ from the calcination process would remain unabated by pre-combustion technologies. Secondly, it requires large modifications to the clinker-burning process for explosive properties of pure hydrogen (OECD/IEA and WBCSD, 2009). Both post-combustion capture and oxy-fuel combustion capture will affect the consumption of thermal energy and electric energy. For instance, post-combustion capture technology based on absorption increases thermal energy consumption by 1000 to $3500 \mathrm{MJ} / \mathrm{t}$ clinker (European Cement Research Academy, 2009). Technically, it will be difficult to commercially deploy postcombustion capture in the cement industry before 2020 due to the high costs incurred, the high environmental risks involved, low $\mathrm{CO}_{2}$ emission price and the lack of public acceptance. It is likely to become a commercial, full-scale option only after 2030. The situation will be difficult to be changed until China takes responsibilities of $\mathrm{CO}_{2}$ reduction after new process of international negotiation.

\section{Methodologies}

In this section, a summary is given of the methodologies applied by authors, introducing the scenario design of developments in the cement sector and methodologies for assessing $\mathrm{CO}_{2}$ mitigation potentials and calculating $\mathrm{CO}_{2}$ avoided costs. The discount rate employed in the study is $10 \%$ and the lifetime for a cement plant is 25 years. Currency rates are calculated based on data from the Bank of China.

\subsection{Scenario design}

Scenario analysis is employed as it can explore probable, possible and preferable futures (Marien, 2002). There are three categories of scenario typology, namely predictive, explorative and normative measures. In this article, explorative measure will be used to explore development in the cement industry, taking annual cement output as the driving force indicator. It is used as it is difficult to make accurate prediction for annual output based on other's research (Jiang and Hu, 2006; Ke et al., 2012; Shi, 2011; Tong et al., 2010). Three scenarios are designed based on the projection of cement output with a 40 -year time horizon (2010-2050). These scenarios are termed the Basic Scenario (BS), Low Carbon Scenario 1 (LC1) and Low Carbon Scenario 2 (LC2). The BS, regarded as the business-as-usual scenario, was set based on current policies and the development trend of cement production. The low carbon scenarios imply that more $\mathrm{CO}_{2}$ mitigation technologies are applied and lower quantities of cement is produced with lower rates of increase in Gross Domestic Product (GDP). The major difference between LC1 and LC2 is the annual capita demand of cement after 2035, which changes the annual output of cement. 2010 is selected as the reference year.

Annual cement output from 2010 to 2015 is calculated based on the linear regression of China's GDP and cement output from 2000 to 2010. It is assumed that GDP will increase 7\% from 2010 to 2015 in the BS. During this period, GDP is the major driver of the output changes. A lower GDP increase rate was specified in LC scenarios, namely 6\% from 2010 to 2015 . It is projected that annual capita demands will peak in 2015 and that annual output after 2015 will depend on annual per capita demand multiplied by the total population (United Nations, 2011). Annual per capita cement demand in each scenario ranges from $0.4 \mathrm{t}$ to $0.6 \mathrm{t}$ after 2035 , approximately resembling that in developed countries (Shi, 2011). Hence, the output from 2035 to 2050 is based on annual per capita cement demand (0.4-0.6t/person in each scenario), multiplied by the total population. From 2015 to 2020, annual capita demands of cement will keep the same like the year 2015. From 2020 to 2035, the annual output is assumed to decrease gradually.

\subsection{Technology development assumption}

The development of $\mathrm{CO}_{2}$ reduction technologies is expressed in the form of their increased rate or share ratio, listed in Table 2. We assume that energy efficiency in the cement sector, including both thermal and electricity energy, will peak in 2040 in the BS and in 2030 in LC scenarios, based on Jiang's research (Jiang, 2011).

The following sections describe the assumptions for the four main efficiency technology groups.

(1) Energy efficiency improvements can reduce the energy intensity of cement. In the BS, energy intensity will decrease from $2.86 \mathrm{GJ} / \mathrm{t}$ cement in 2010 (Quantitative Economics and Audit Society of China, 2011) at a fixed annual reduction rate until it drops to $2.19 \mathrm{GJ} / \mathrm{t}$ cement in 2040 . The best thermal energy efficiency ranges from 2.9 to $3.3 \mathrm{GJ} / \mathrm{t}$ clinker. In our assumptions, the best electricity efficiency is set at $80 \mathrm{kWh} / \mathrm{t}$ cement. Considering the clinker-to-cement ratio, which ranges from 0.59 to 0.63 , the energy intensity (including both thermal and electricity) produced by the best technology ranges from 2.0 to $2.36 \mathrm{GJ} / \mathrm{t}$ cement; $2.19 \mathrm{GJ} / \mathrm{t}$ cement lies within this range. According to current policy, the aim is to achieve an energy intensity of $2.73 \mathrm{GJ} / \mathrm{t}$ cement by 2015 in BS (2011a).

In $201055 \%$ of WHR was equipped with NSP; this percentage will increase to 65\% in 2015 (2011a). We assume that it will be 
Table 2

Technology development assumption in various scenarios.

\begin{tabular}{|c|c|c|c|c|c|c|c|c|c|}
\hline Scenario & Item & Indicator & Unit & 2010 & 2015 & 2020 & 2030 & 2040 & 2050 \\
\hline \multirow[t]{6}{*}{ BS } & $\begin{array}{l}\text { Energy efficiency } \\
\text { improvement }\end{array}$ & Energy intensity & $\mathrm{GJ} / \mathrm{t}$ cement & $2.86^{\mathrm{a}}$ & $2.73^{\mathrm{b}}$ & 2.61 & 2.4 & 2.19 & $2.19^{c}$ \\
\hline & $\begin{array}{l}\text { Electric energy efficiency } \\
\text { improvement }\end{array}$ & Electricity intensity & kWh el/t cement & $89^{a}$ & 88 & 86 & 83 & 80 & $80^{d}$ \\
\hline & WHR & Share of total production & $\%$ & $55^{\mathrm{b}}$ & $65^{\mathrm{b}}$ & 72 & 86 & 100 & 100 \\
\hline & Alternative fuels & Share of total production & $\%$ & 0 & 2.0 & 4.5 & 9.5 & 14.5 & $23.5^{\mathrm{e}}$ \\
\hline & Clinker substitution ratio & Clinker to cement ratio & 1 & $0.630^{\mathrm{f}}$ & 0.629 & 0.628 & 0.625 & 0.623 & $0.620^{\mathrm{e}}$ \\
\hline & CCS & Share of cement output & $\%$ & 0 & 0 & 0 & 0 & 0 & 0 \\
\hline \multirow[t]{6}{*}{ LC1 } & $\begin{array}{l}\text { Energy efficiency } \\
\text { improvement }\end{array}$ & Energy intensity & $\mathrm{GJ} / \mathrm{t}$ cement & 2.86 & 2.69 & 2.52 & 2.19 & 2.19 & 2.19 \\
\hline & $\begin{array}{l}\text { Electric energy efficiency } \\
\text { improvement }\end{array}$ & Electricity intensity & kWh_el/t cement & 89 & 87 & 85 & 80 & 80 & 80 \\
\hline & WHR & Share of total production & $\%$ & 55 & 65 & 77 & 100 & 100 & 100 \\
\hline & Alternative fuels & Share of total production & $\%$ & 0 & 4.5 & 9.0 & 17.4 & 25.8 & $34.0^{\mathrm{e}}$ \\
\hline & Clinker substitution ratio & Clinker to cement ratio & 1 & 0.630 & 0.626 & 0.623 & 0.615 & 0.607 & $0.600^{e}$ \\
\hline & CCS & Share of cement output & $\%$ & 0 & 0 & 0 & 10 & 30 & $50^{e}$ \\
\hline \multirow[t]{6}{*}{ LC2 } & $\begin{array}{l}\text { Energy efficiency } \\
\text { improvement }\end{array}$ & Energy intensity & $\mathrm{GJ} / \mathrm{t}$ cement & 2.86 & 2.69 & 2.52 & 2.19 & 2.19 & 2.19 \\
\hline & $\begin{array}{l}\text { Electric energy efficiency } \\
\text { improvement }\end{array}$ & Electricity intensity & kWh_el/t cement & 89 & 87 & 85 & 80 & 80 & 80 \\
\hline & WHR & Share of total production & $\%$ & 55 & 65 & 77 & 100 & 100 & 100 \\
\hline & Alternative fuels & Share of total production & $\%$ & 0 & 5 & 9 & 18 & 27 & $36^{e}$ \\
\hline & Clinker substitution ratio & Clinker to cement ratio & 1 & 0.630 & 0.625 & 0.620 & 0.610 & 0.600 & $0.590^{\mathrm{e}}$ \\
\hline & CCS & Share of cement output & $\%$ & 0 & 0 & 0 & 10 & 30 & $50^{e}$ \\
\hline
\end{tabular}

More information: $1 \mathrm{kgce}=29.3 \mathrm{MG} / \mathrm{kg}, 1 \mathrm{kWh}=3600 \mathrm{~kJ}$.

a Quantitative Economics and Audit Society of China, 2011b.

b 2011a.

c Strategic Energy Technologies Information System, 2011.

d WWF (2008).

e OECD/IEA and WBCSD (2009).

f Zeng (2011).

$100 \%$ by 2040 in the BS, and $100 \%$ by 2030 in the LC scenarios. The electricity generated by WHR for each scenario is 10,15 and $20 \mathrm{kWh} / \mathrm{t}$ clinker, respectively.

(2) Use of alternative fuels will share 2\% in 2015 in the BS (Shi, 2011 ); this proportion will increase annually by $0.5 \%$ from 2015 to 2030 . After 2040, it will increase by $0.9 \% / a$, resembling the ratio achieved in developed countries. In LC1 and LC2, the annual increase ratio will be $0.85 \%$ and $0.9 \%$ from 2010 to 2050 , respectively. This results in a final share of $34 \%$ and $36 \%$, which is identical to the results of IEA Roadmap high demand and low demand scenarios (OECD/IEA and WBCSD, 2009). Regarding the importance of biomass and tyres, to keep matters simple we assume they will account for half of all alternative fuels each, with a substitution ratio of $20 \%$ (WBCSD, 2009).

(3) Clinker substitution mainly refers to the use of BFS, fly ash and limestone. In the process, it is assumed that supply is able to satisfy production demand. In 2010, the clinker-to-cement ratio was 0.63 (Zeng, 2011), bettering the value of 0.72 produced in the IEA Roadmap. The accumulative reduction of clinker to cement ratios from 2010 to 2050 in the BS, LC1 and LC2 scenarios are $1 \%, 3 \%$ and $4 \%$, respectively. This change was assumed because the total reduction potential of the clinker-to-cement ratio from 2010 to 2050 ranges from $1 \%$ to $4 \%$, according to the IEA Roadmap (OECD/IEA and WBCSD, 2009).

(4) CCS application ratio is also based on the IEA Roadmap (OECD/IEA and WBCSD, 2009), which is assumed to increase from $10 \%$ to $50 \%$ of cement production between 2030 and 2050 . Its commercial deployment is set to commence in 2030. CCS in retrofitted plants is not considered due to the cost, technology and production situation. We assume that the CCS technologies used in China are half post-combustion capture and half oxy-fuel combustion capture. Based on research conducted by Europe Cement Research Academy (ECRA) (CSI/ECRA, 2008), it is assumed that post-combustion capture by absorption will increase thermal energy consumption by $3000 \mathrm{MJ} / \mathrm{t}$ clinker and electricity consumption by $60 \mathrm{kWh} / \mathrm{t}$ clinker. For oxy-fuel combustion CCS, we assume that an additional quantity of $100 \mathrm{MJ} / \mathrm{t}$ clinker thermal and $110 \mathrm{kWh} / \mathrm{t}$ clinker electric energy is required.

\section{3. $\mathrm{CO}_{2}$ reduction assessment}

The quantity of $\mathrm{CO}_{2}$ avoided annually by each measure is calculated by multiplying energy intensity reduction by cement output and fuel to $\mathrm{CO}_{2}$ emission factors, which is shown in the following equation:

$\mathrm{CO}_{2}=\Delta E \times$ Output $\times \mathrm{F}_{\mathrm{CO}_{2}}$

where $\mathrm{CO}_{2}$ stands for $\mathrm{CO}_{2}$ avoided annually, $\Delta E$ is the energy intensity reduction, and $\mathrm{F}_{\mathrm{CO}_{2}}$ is $\mathrm{CO}_{2}$ emission factor.

(1) Energy intensity reduction is the most important indicator because all reduction measures can affect energy intensity in both the energy consumption and calcination process.

(2) We assume that 1 tonne of biomass can offset 2.62 tonnes of $\mathrm{CO}_{2}$ and that 1 tonne of tyres can offset 0.8 tonnes of $\mathrm{CO}_{2}$ when they replace 1 tonne of coal (Murray and Price, 2008). The quantity of $\mathrm{CO}_{2}$ offset by biomass and tyres can be calculated by multiplying the assumed application ratio by the substitution ratio.

(3) The quantity of $\mathrm{CO}_{2}$ avoided by clinker substitution is obtained from the reduced clinker-to-cement ratio multiplied by the $\mathrm{CO}_{2}$ emission factors from each process.

(4) In terms of $\mathrm{CO}_{2}$ avoided by CCS, we mainly use the avoided ratio multiplied by the emission amount to calculate the quantity of $\mathrm{CO}_{2}$ captured. $\mathrm{CO}_{2}$ avoided reflects the amount of $\mathrm{CO}_{2}$ prevented from being emitted, and the relation with $\mathrm{CO}_{2}$ capture is clearly expressed in Fig. 1, taken from (Singh et al., 2011). 


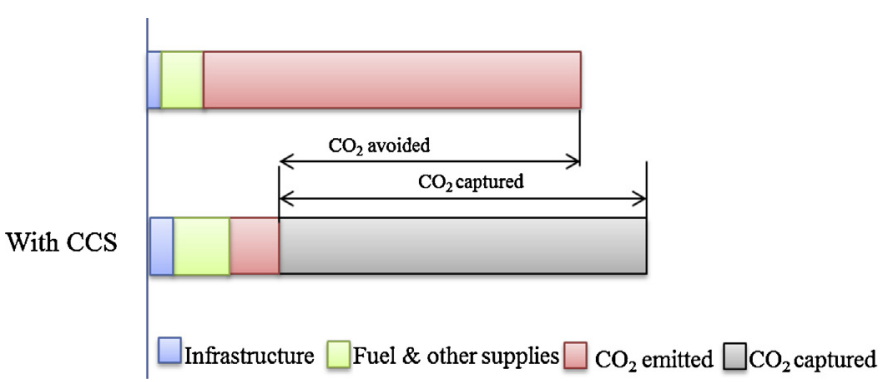

Fig. 1. $\mathrm{CO}_{2}$ accounting.

The avoided ratios for post-combustion capture and oxy-fuel combustion capture are $74 \%$ and $61 \%$, respectively (Barker et al., 2009).

\subsection{Cost analysis}

It is important to conduct a cost analysis to compare the cost efficient of each energy efficiency technology and measure, which includes coal, electricity, raw materials, and capital cost etc. The costs of fuel and electricity accounts for the largest proportions of the total cost of cement production. In the future, when the price of fuel and electricity rises, the cost of cement will increase accordingly. However, because it is not easy to find how the technology changes, such as their learning rates, in our study, we assume that the costs of energy efficiency improvement and other measures keep the same like those in Table 1 until 2050.

Since we focus on a technology assessment rather than on an energy structure assessment, we assume that electricity is generated from power plants only and that thermal energy is produced by burning coal. Firstly, $75 \%$ of the electricity in China is produced from coal, and this situation will not change in a short term. Secondly, the electricity price in China follows the policy named "coal and electricity price linkage mechanism", which means that the electricity price will change based on coal price. Annual price increase rate of coal is assumed to be $2 \%$, because it is ranged from $0 \%$ to $3 \%$ in references (Greenpeace Energy revolution, 2007; Wang and Zhang, 2011). We assume that the price of tyres will increase in line with biomass. Price of coal is calculated based on the data in 2010, and tyres and biomass prices are from market survey (China Coal Resource, 2012). The prices of BFS, fly ash and limestone are taken from the study of (Ernst Worrell et al., 2008), assuming an annual increase rate of $0.5 \%$. The starting costs of coal, electricity, biomass, tyres, BFS, fly ash and limestone in 2010 are $846 \mathrm{RMB} / \mathrm{t}, 0.75 \mathrm{RMB} / \mathrm{t}, 350 \mathrm{RMB} / \mathrm{t}, 1200 \mathrm{RMB} / \mathrm{t}, 54 \mathrm{RMB} / \mathrm{t}, 28 \mathrm{RMB} / \mathrm{t}$ and $25 \mathrm{RMB} / \mathrm{t}$. The costs for post-combustion capture and oxy-fuel combustion capture in 2010 are 357 and $234 \mathrm{RMB} / \mathrm{t}$, which is transferred from the IEA study (Barker et al., 2009). The currency rate between US dollars and Chinese RMB was 6.84 RMB/dollar in the year 2010.

The main equations required to calculate the costs are:

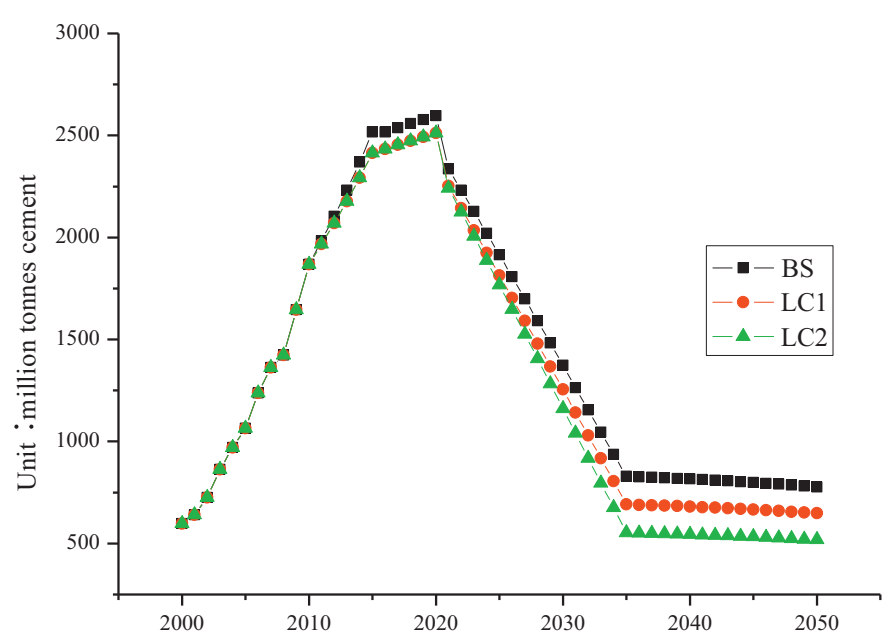

Fig. 2. Output of cement from 2000 to 2050 in different scenarios.

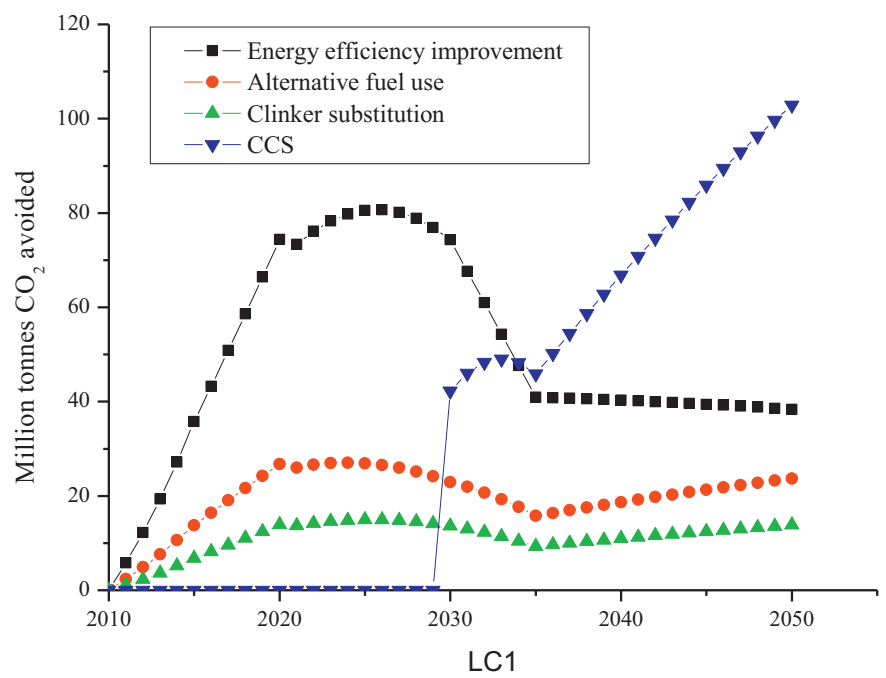

Fig. 3. Quantity of $\mathrm{CO}_{2}$ avoided annually from 2010 to 2050 in low carbon scenario

\subsection{Output projection}

Fig. 2 shows that cement output peaks in 2020 in both the BS and LC scenarios, where per capita cement demand reaches 1.76 and $1.7 \mathrm{t}$, respectively. The main reason for this increase is strong economic growth. After 2020, production declines sharply until 2035 , caused mainly by the slower economy development rate. After 2035, citizen requirements of cement are the major driver of the output.

Total_cost $_{\text {current }}=$ Cost $_{\text {fuel }}+$ Cost $_{\text {electricity }}+\operatorname{Cost}_{\mathrm{OM}}+$ Cost $_{\text {capital }}$

Total_cost ${ }_{\text {after }}=$ Cost $_{\text {fuel }}+$ Cost $_{\text {electricity }}+$ Cost $_{\text {OM }}+$ Cost $_{\text {capital }}+$ Cost $_{\text {technology }}$

$\mathrm{CO}_{2 \text { _avoided_cost }}=\left(\mathrm{Cost}_{\text {after }} / \mathrm{CO}_{\text {2avoided }}-\mathrm{CO}_{2 \text { reference }} / \mathrm{CO}_{\text {2avoided }}\right)=\mathrm{Cost}_{\text {avoided }} / \mathrm{CO}_{\text {2avoided }}$

\section{Results}

In this section, the cement output in each scenario is projected from 2010 to 2050 . The measures' $\mathrm{CO}_{2}$ emission reduction potentials are presented and the $\mathrm{CO}_{2}$ avoided costs of these technologies comparied.

\section{2. $\mathrm{CO}_{2}$ reduction}

The quantity of annual $\mathrm{CO}_{2}$ emissions mainly depends on the production of cement output and the emission reduction per tonne cement, which are the major reasons for changes to the curves. 


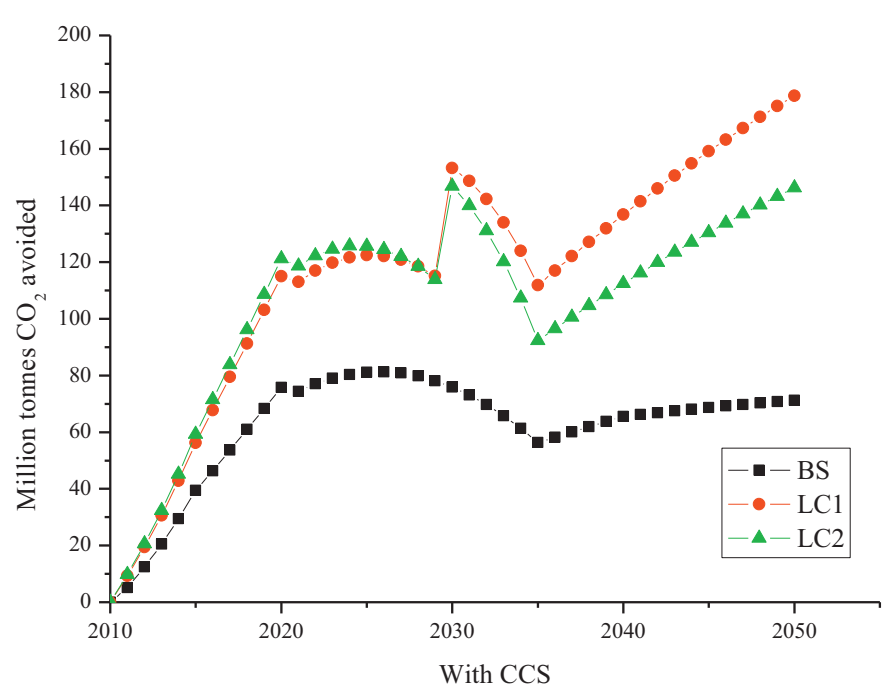

Fig. 4. Annual $\mathrm{CO}_{2}$ reduction generated in basic and low carbon scenarios.

Using the example of scenario LC1, Fig. 3 shows which $\mathrm{CO}_{2}$ emissions could be saved annually from 2010 to 2050 due to the reduction measures considered above. During this period, 2039, $804,452,1446$ million tonnes of $\mathrm{CO}_{2}$ can be saved totally by energy efficiency improvement, use of alternative fuels, clinker substitution, and CCS, respectively. The trends of $\mathrm{CO}_{2}$ avoided per technology over time all increase to their own peaks, and then start to reduce. After around 2035, the curves of the use of alternative fuel, clinker substitution and CCS increase again.

(1) 80.7 million tonnes of $\mathrm{CO}_{2}$ can be saved annually by energy efficiency improvements, peaking around 2026. The curve declines up to 2035, after which it remains almost stable. The amount of $\mathrm{CO}_{2}$ avoided by WHR is not very large compared to the other technologies, because electricity accounts for a small part of energy consumption. The overall trend is similar to that created by energy efficiency improvements, but generates only small changes.

(2) Use of alternative fuels helps reduce $\mathrm{CO}_{2}$. Its development trend is not dissimilar to that of energy efficiency improvements. After 2035, the annual amount of $\mathrm{CO}_{2}$ mitigated increases slightly.

(3) Clinker substitution leads to a lower reduction of $\mathrm{CO}_{2}$ emissions than energy efficiency improvements and use of alternative fuels. The largest quantity of $\mathrm{CO}_{2}$ will be reduced in 2025, then the reduction amount will gradually decline up to 2035. After that, the annual reduction capacity will increase to 13.8 million tonnes of $\mathrm{CO}_{2}$ in 2050.

(4) CCS will become commercially available in 2030, leading to an obvious change in the total $\mathrm{CO}_{2}$ reduction ability in the LC scenarios. After 2033, the annual quantity of emissions saved by CCS decreases, mainly due to the drop in cement output. The subsequent increase in captured emissions is due to the more widespread application of CCS. Hence, any change to the development trend of the curves is affected by either the application of technology or the rate of cement production.

It can be found that a total of $2.5,4.7$ and $4.3 \mathrm{Gt}$ tonnes of $\mathrm{CO}_{2}$ will be saved in the respective scenarios up to 2050 shown in Fig. 4. It also shows the annual $\mathrm{CO}_{2}$ reduction generated by these measures with CCS. The emission reduction curves initially rise and then decline in all scenarios. Reductions peak at around 2025; the other inflection point is 2035 , which strongly signifies the impact of cement output. There are two significant reversal points in 2030

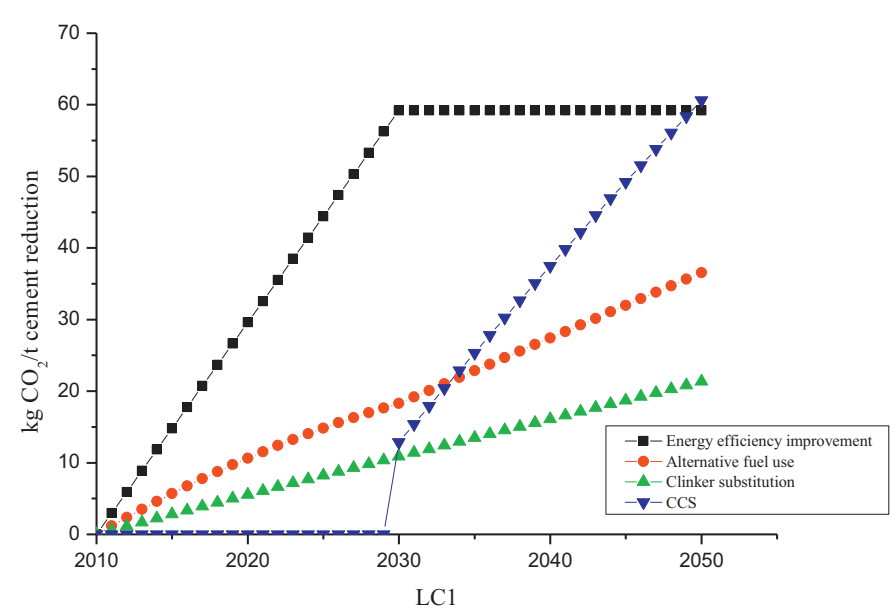

Fig. 5. $\mathrm{CO}_{2}$ intensity reduced by each technology in low carbon scenario 1 .

and 2035. The first inflection point is due to the introduction of CCS, whereas the second is caused mainly by a more widespread use of CCS. The reduction in emissions between 2030 and 2035 is affected by a reduction in output. Background information is that most advanced cement plants were built during 2005-2010 in China, and their lifetime is 25 years. Moreover, based on the assumption in Table 2, there is a sudden increase around 2030.

However, although use of CCS consumes additional energy, Fig. 5 indicates that, neglecting the impact of cement demand, energy efficiency improvements, use of alternative fuels and CCS can greatly reduce $\mathrm{CO}_{2}$ intensity, which is transferred from energy intensity per cement multiplied by emission factor. Increased over time, until 2050 the total reduction of $\mathrm{CO}_{2}$ intensity per cement by energy efficiency improvement, use of alternative fuel, clinker substitution and CCS are $59.2 \mathrm{kgCO}_{2} / \mathrm{t}, 36.6 \mathrm{kgCO}_{2} / \mathrm{t}, 21.3 \mathrm{kgCO}_{2} / \mathrm{t}$ and $60.6 \mathrm{kgCO}_{2} / \mathrm{t}$, respectively.

\subsection{Cost comparison}

The $\mathrm{CO}_{2}$ avoided cost of each measure in $\mathrm{LC} 1$ is selected as an example (shown in Fig. 6).

Firstly, it is easy to determine from Fig. 6 that some costs are positive and others negative. Positive cost means that additional costs are incurred by the use of technology; negative cost indicates that the technology applied saves more in total than it costs. At the start, in 2011, for example, the avoided costs of alternative fuels and CCS are positive whereas the avoided cost of energy efficiency improvements and clinker substitution is negative.

Secondly, $\mathrm{CO}_{2}$ avoided cost changes over time. (1) From 2011 to 2050 , the avoided cost caused by energy efficiency improvements declines is from 0.4 to $-15.7 \mathrm{RMB} / \mathrm{t} \mathrm{CO}_{2}$. This figure implies that energy efficiency improvements should be considered as a reduction measure at all times. (2) The avoided costs caused by use of biomass and tyres show similar development trends. Despite a number of minor fluctuations, the avoided cost caused by use of biomass and tyres changes from 0.7 to $-2.3 \mathrm{RMB} / \mathrm{t} \mathrm{CO}_{2}$, and 10.5 to $20.9 \mathrm{RMB} / \mathrm{t} \mathrm{CO}_{2}$ from 2011 to 2050. (3) The avoided costs of three types of clinker substitution decline initially and then increase. In 2050, the avoided cost of clinker substitution by BFS increases from negative to positive, peaking at $122.8 \mathrm{RMB} / \mathrm{t} \mathrm{CO} 2 . \mathrm{CO}_{2}$ reduction costs caused by fly ash and limestone will be -131.1 and $-166.3 \mathrm{RMB} / \mathrm{t} \mathrm{CO}_{2}$, respectively. (4) In 2030, $\mathrm{CO}_{2}$ avoidance costs by post- combustion and oxy-fuel combustion CCS are 406.2 and 266.6 RMB/ $/ \mathrm{CO}_{2}$, which could increase to 412.5 and $270.7 \mathrm{RMB} / \mathrm{t}$ $\mathrm{CO}_{2}$ in 2050. 


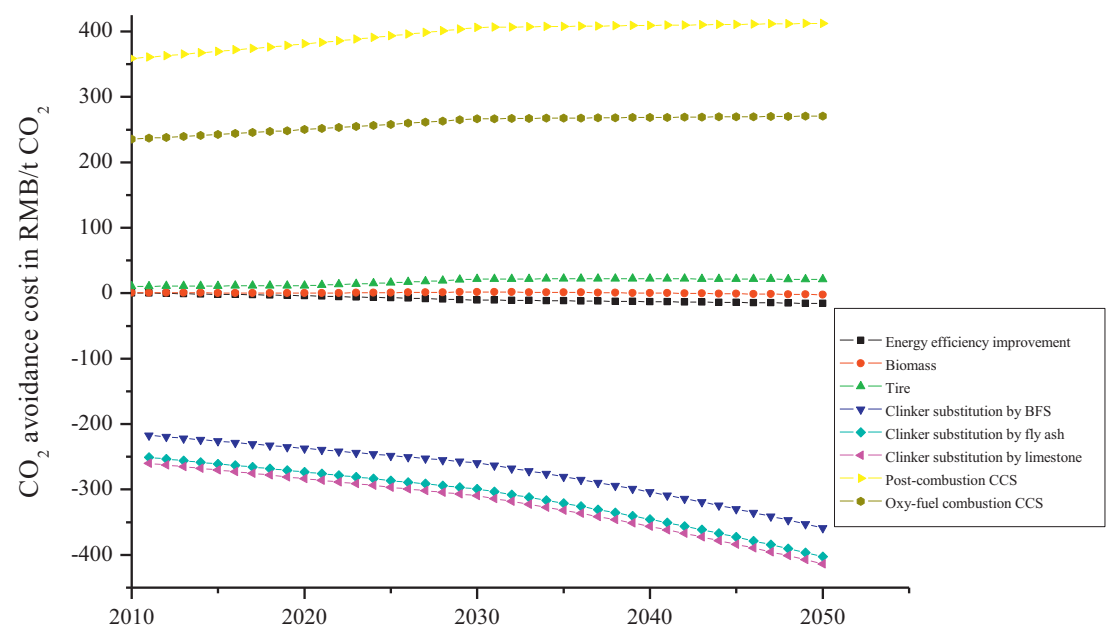

Fig. 6. $\mathrm{CO}_{2}$ avoided cost of each technology in low carbon scenario 1 .

As we can see from Fig. 6, the trends of $\mathrm{CO}_{2}$ avoidance costs of each technology are different. The avoidance costs of clinker substitution show an obvious decline, while changes of other technology are gently. When energy efficiency, use of alternative fuels and clinker substitution are included, the cost of avoidance during the initial years usually decreases. This signifies that enormous costs can be saved during this period, mainly because these three technologies lead to a reduction in energy generated from burning fuel or from the electricity process. The $\mathrm{CO}_{2}$ avoidance costs by these technologies change only slightly, indicating that the joint effects of the fuel price and the quantity of $\mathrm{CO}_{2}$ avoided on the cost reduction are not particularly apparent. CCS, which always costs the most, should be the last option to mitigate $\mathrm{CO}_{2}$.

\section{Discussion}

\subsection{Comparison of energy intensity and $\mathrm{CO}_{2}$ reduction}

Three scenarios were designed based on the projection of the annual output of cement. Although several studies have been conducted on future output developments (OECD/IEA and WBCSD, 2009), the development of China's cement sector is underestimated (Ke et al., 2012). Hence, we decided to project the development ourselves, leading to different mitigation scenarios.

(1) Energy efficiency improvements play a key role in reducing $\mathrm{CO}_{2}$, which can save $72 \%$ of total $\mathrm{CO}_{2}$ emissions in the $\mathrm{BS}, 43 \%$ in LC1 and $43 \%$ in LC2. In the first few decades, energy efficiency will improve due to the construction of new facilities using the NSP technique and the closure of old production sites. Thereafter, greater efforts should be made to spread new technology, as discussed above (Hasanbeigi et al., 2010b). Although WHR can save electricity, the role it plays in reducing $\mathrm{CO}_{2}$ is limited, as the emission from electricity constitutes only a small share of the total. We also assume that all electricity is generated from coal plants. However, the actual energy structure in China will change in the future. We neglected its influence on $\mathrm{CO}_{2}$ reduction, though, because we focused on assessing technology.

(2) Use of alternative fuels has a great potential for reducing $\mathrm{CO}_{2}$, constituting $21 \%, 17 \%$ and $18 \%$ of total amount of emissions saved in BS, LC1 and LC2, respectively. We assume that use of alternative fuels refers to biomass and tyres. In actual fact, other alternative fuels exist, such as chemical and hazardous waste, and the quantity of $\mathrm{CO}_{2}$ they reduce depends on their emission factors. In some European countries, however, substitution rate of alternative fuels can constitute more than 50\% (OECD/IEA and WBCSD, 2009). In China, use of alternative fuels is still in its infancy. A 20\% substitution ratio is assumed and it has even greater potential for improvement, which could reduce $\mathrm{CO}_{2}$ emissions even further.

(3) Although clinker substitution is a direct way to reduce $\mathrm{CO}_{2}$ emissions, China should concentrate more on improving product quality, which can be directly impacted by the clinker to cement ratio. Up to 2050, clinker substitution can save 170.5 , 452.1 , and 622.5 million tonnes of $\mathrm{CO}_{2}$, accounting for only $7 \%$, $10 \%$ and $14 \%$ of total emissions in each scenario.

(4) Additional thermal and electricity energy for CCS is required, equalling 2.0 and $0.3 \mathrm{GJ} / \mathrm{t}$ cement. When the deployment of CCS becomes widespread, avoidance rates will increase, leading to a greater reduction in $\mathrm{CO}_{2}$ emissions. In the $\mathrm{LC}$ scenarios, technology is applied at a greater rate. Use of CCS in particular saves 1.4 and $1.2 \mathrm{Gt} \mathrm{CO}_{2}$ in $\mathrm{LC} 1$ and LC2 up to 2050, representing $32 \%$ and $27 \%$ of the total amount. $\mathrm{CO}_{2}$ avoided by post-combustion CCS and oxy-fuel combustion CCS accounts for $55 \%$ and $45 \%$ of the total quantity of captured emissions.

\subsection{Cost comparison}

Cost data is compiled from other studies, including capital costs and operational and maintenance (OM) costs etc. Energy costs, especially for coal and electricity, have a major impact on cement costs due to their share of the cost structure. LC1 is selected as an example, presenting the $\mathrm{CO}_{2}$ avoidance costs generated by different measures. All the costs from the other study are transferred into RMB by using the currency rate published by the Bank of China.

(1) The $\mathrm{CO}_{2}$ avoidance cost generated by energy efficiency improvements declines over time, and is always negative and cost-effective. This means that energy efficiency improvements always generate benefits. However, this assessment is based on 10 selected technologies. If all the available technologies were considered, the overall cost would be positive. It is not easy to compare our figures with other studies because they use different methodologies, select different technologies and compile different types of data. According to research conducted by LBNL, the $\mathrm{CO}_{2}$ abatement costs of 28 technologies in Thai cement are negative $(-500.6$ to $-9.3 \mathrm{RMB} / \mathrm{t} \mathrm{CO}$ ) (Hasanbeigi et al., 2010a). In North America, process upgrading to convert wet kiln to semi-wet or dry processes for the greater use of preheaters and precalciners is still believed to be a promising 


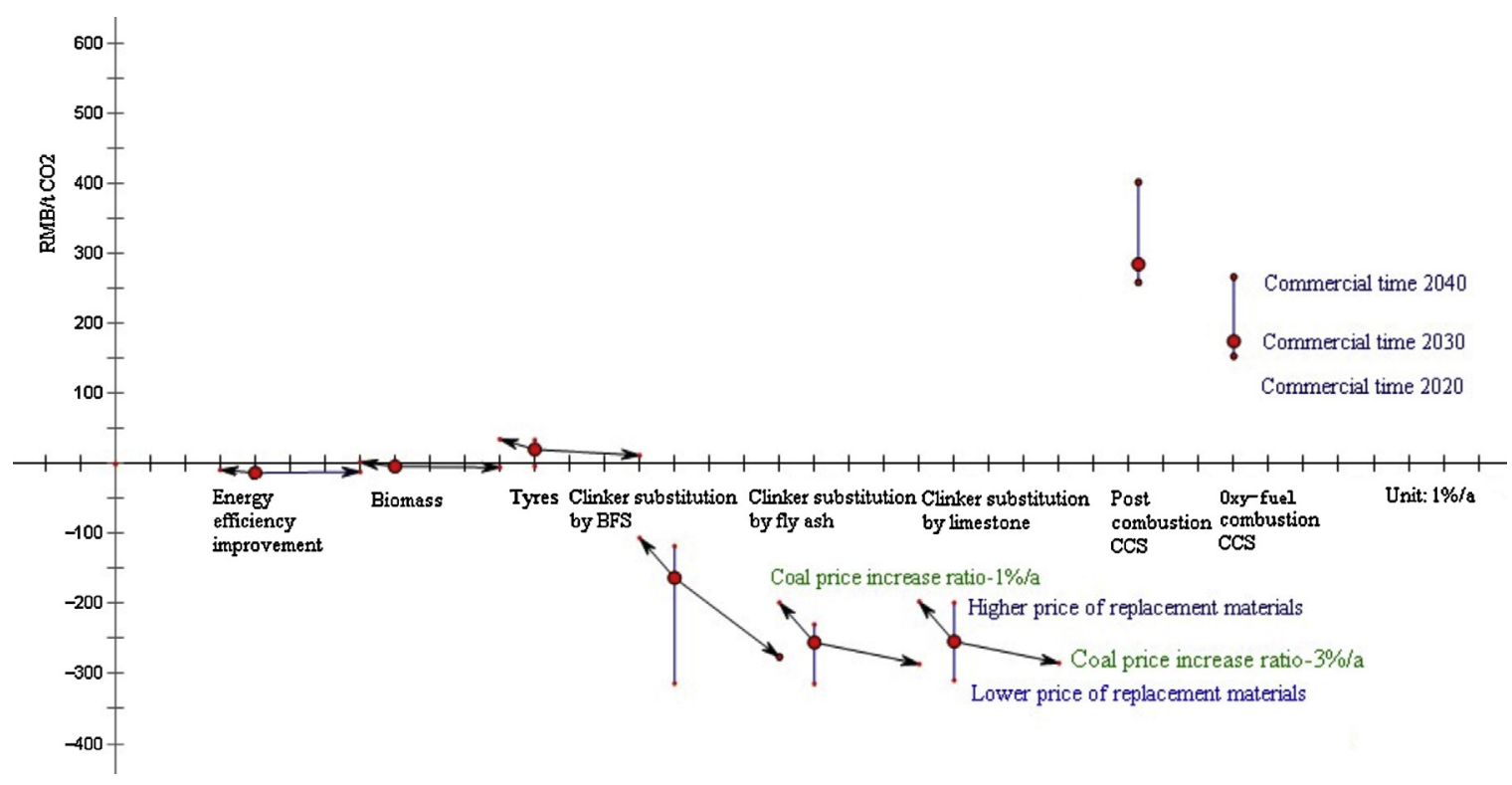

Fig. 7. Sensitivity analysis of $\mathrm{CO}_{2}$ avoidance costs caused in 2030 in low carbon scenario 1 .

option to reduce $\mathrm{CO}_{2}$ with a positive cost below $244.2 \mathrm{RMB} / \mathrm{t}$ $\mathrm{CO}_{2}$ (Mahasenan et al., 2005). Gu et al. assessed 16 types of energy efficiency improvement technologies by using Marginal Abatement Cost Curve, and their costs were ranged from -1557 to $236 \mathrm{RMB} / \mathrm{t} \mathrm{CO} 2$ (Gu et al., 2012).

(2) The $\mathrm{CO}_{2}$ avoidance costs generated by use of biomass and tyres have the similar decreasing trend; biomass generates greater cost benefits than tyres. In most cases, the avoided cost from use of biomass is negative and that from use of tyres positive. This difference is mainly due to the price and heating value of fuel. Use of biomass in Thailand's cement sector is not regarded as a cost-effective measure (Hasanbeigi et al., 2010a). In Mahasenan et al.'s study, fuel switching is suggested in the cement sector to reduce $\mathrm{CO}_{2}$ emissions as they assume zero additional cost (Mahasenan et al., 2005). McKinsey \& Company believes that $\mathrm{CO}_{2}$ avoided cost generated by biomass is positive (less than $-5 \mathrm{USD} / \mathrm{t} \mathrm{CO}_{2}$ in 2030) and cost by waste is negative (around $-10 \mathrm{USD} / \mathrm{t} \mathrm{CO}_{2}$ in 2030) (McKinsey and Company, 2009). In Gu et al.'s research, the cost of alternative fuel use is $-108 \mathrm{RMB} / \mathrm{t}$ $\mathrm{CO}_{2}$ (Gu et al., 2012).

(3) The $\mathrm{CO}_{2}$ avoidance cost resulting from clinker substitution by BFS, fly ash and limestone follows a similar development trend. Prior to 2016, the cost reduction is caused by the low price of substitution materials, and the increase is due to the cost of energy. The avoided cost of BFS will be positive after 2044 , implying that it is no longer cost effective after that. The research conducted by McKinsey and Company indicates that the $\mathrm{CO}_{2}$ avoided costs of clinker substitution by fly ash, slag and other mineral components in 2030 are all negative (McKinsey and Company, 2009). Clinker substitution should be considered first because it incurs the lowest negative cost. However, it is not easy to implement these measures on a large scale for technological and production quality reasons.

(4) Oxy-fuel combustion CCS is preferred economically because it costs less than post-combustion CCS. The avoided cost of postcombustion $\mathrm{CO}_{2}$ capture and oxy-fuel combustion $\mathrm{CO}_{2}$ capture will increase slightly up to 2050 due to a reduction in energy intensity. Many elements can influence its cost, such as the rate of avoided cost and learning effects, which we will discuss later.

The original data concerning CCS costs are based on research conducted by IEA Greenhouse Gas R\&D Programme (IEA GHG).
According to their research, the $\mathrm{CO}_{2}$ avoided cost by postcombustion $\mathrm{CO}_{2}$ capture and oxy-fuel combustion $\mathrm{CO}_{2}$ capture in Asian developing countries in 2009 was 401.2 and $156.4 \mathrm{RMB} / \mathrm{t}$ $\mathrm{CO}_{2}$, respectively, based on the assumption of the application of CCS in EU cement production (Barker et al., 2009). Hegerland (2006) estimate the cost per capture to be $455.9 \mathrm{RMB} / \mathrm{t} \mathrm{CO}_{2}$ for post-combustion capture based on retrofitting plants (Hegerland, 2006). Mahasenan et al. (2005) argue that the minimum cost is $407 \mathrm{RMB} / \mathrm{t} \mathrm{CO}_{2}$ for US plants (Mahasenan et al., 2005). Zeman and Lackner (2008) assess the minimum capture cost at between 105.9 and $127.1 \mathrm{RMB} / \mathrm{t}$ for $\mathrm{CO}_{2}$ captured by oxy-fuel (Zeman and Lackner, 2008). Moreover, OECD/IEA estimated that the cost of new and retrofitted post-combustion capture would range from 529.5 to $706 \mathrm{RMB} / \mathrm{t} \mathrm{CO}_{2}$ in 2008 (OECD/IEA, 2008). ECRA (2008) and Mckinsey (2009) also conducted cost assessments for CCS in the cement sector, but these studies involved a general estimation of investment and operation and maintenance costs after 2030 (European Cement Research Academy, 2009; Hegerland, 2006; McKinsey \& Company, 2009; VDZ Research Institute of the Cement Industry and PENTA Engineering Corp, 2008). Liang calculated that the avoided cost of CCS in retrofitting plant in 2012 is $440.3 \mathrm{RMB} / \mathrm{t} \mathrm{CO}_{2}$ with 25 years remaining lifetime (Liang and $\mathrm{Li}, 2012$ ). Dahowski et al. found out that among China's industrial and electric power sectors, capture cost was from $0 \mathrm{RMB} / \mathrm{t} \mathrm{CO}_{2}$ to over $353.5 \mathrm{RMB} / \mathrm{t} \mathrm{CO}_{2}$, and the highest cost sources are refineries and cement plants etc. (Dahowski et al., 2012). Gu et al. evaluated that the cost of CCS in cement sector is only $36 \mathrm{RMB} / \mathrm{t} \mathrm{CO} \mathrm{CO}_{2}(\mathrm{Gu}$ et al., 2012). However, we establish that the cost of CCS in China's cement sector is no higher than in other countries. It remains difficult to compare these figures with CCS in other industries because different studies yield different cost ranges (Element Energy, 2010).

\subsection{Sensitivity analysis}

Sensitivity analysis was conducted by changing relevant parameters such as the price of energy, the price of raw materials and when CCS will become commercially available for LC1. After all, these factors play an important role in causing cost changes. Prices vary depending on the region, production type, market environment, and so on. The $\mathrm{CO}_{2}$ avoidance costs of different measures in 2030 were analyzed, as shown in Fig. 7. 
The red points stand for the $\mathrm{CO}_{2}$ avoidance costs caused by each measure in LC1 in 2030 under reference conditions. The points, directed by arrows pointing left or right, show the cost deviation due to an increase or decrease in the relevant parameters compared to the reference case. The $x$-intercept of the arrow pointing right is three times longer than that pointing left. They stand for a 3\%/a and $1 \% / a$ increase rate of the price of coal.

In the event of energy efficiency, alternative fuel and clinker substitution, the price of coal increases by $1 \% / \mathrm{a}$ and $3 \%$ a were tested. We find that the energy price (including coal and electricity) has the greatest impact on the $\mathrm{CO}_{2}$ avoided cost of clinker substitution and a lower impact on that of energy efficiency improvements and use of alternative fuels. The reason for this difference is that the $\mathrm{CO}_{2}$ avoidance cost caused by energy efficiency improvements and use of alternative fuels is lower. In contrast, the cost of clinker substitution is greatly influenced by the energy price and the energy price has no impact on the $\mathrm{CO}_{2}$ avoidance cost caused by CCS when the price of coal changes increases by $3 \% / \mathrm{a}$ or $1 \% / \mathrm{a}$. The main reason for this is that when coal prices change, the reference cost of cement changes simultaneously.

We also analyse the impact of alternative fuel prices and raw material prices on the avoided cost. The price of biomass and tyres is assumed to increase annually by $3 \%$ and $0.5 \%$, which we consider to be the maximum and minimum increase rate. However, because their $\mathrm{CO}_{2}$ avoided cost is not very high and since alternative fuels only replace $20 \%$ of coal, the impact of fuel prices on the $\mathrm{CO}_{2}$ avoided cost is not very large. Sensitivity analysis of annual increase prices of substitution materials is assumed to be $0.1 \%, 3 \%$ and $5 \%$. The more alternative fuels cost, the more costs are avoided. For example, the avoided cost caused by BFS is higher than other two because BFS is more expensive. When the annual increase ratio becomes $5 \%$, several years later, the avoided cost for tyres and BFS is positive. This fact suggests that when the price of substitution materials increases to certain level, the advantage of its avoided cost will disappear.

The year 2030 is assumed to be the commercial time of CCS. The availability in 2020 and 2040 is used for sensitivity analysis aiming to find out the different commercial time of CCS. Learning curve effects are considered when the technology becomes commercially applied and the data of learning rates come from references (Singh et al., 2011; Wuppertal, 2012). When the commercial time is 2020, 2030 and 2040, its $\mathrm{CO}_{2}$ avoided cost in LC1 in 2030 is 268.4, 294.7 and 406.2 RMB/t $\mathrm{CO}_{2}$ for post-combustion CCS and 157.7, 178.5 and 266.6 RMB/t $\mathrm{CO}_{2}$ for oxy-fuel combustion CCS.

\section{Conclusion}

Four types of $\mathrm{CO}_{2}$ reduction technologies in China's cement sector were evaluated in this article, namely energy efficiency improvements, use of alternative fuels, clinker substitution and CCS with regard to their reduction potential and economic cost. Three future scenarios based on annual output in the cement sector were designed and a low carbon pathway was suggested to increase $\mathrm{CO}_{2}$ reduction. Until 2050, 2.5, 4.7 and $4.3 \mathrm{Gt}$ tonnes of $\mathrm{CO}_{2}$ will be saved totally in the basic scenario and the two low carbon scenarios respectively. Energy efficiency improvements should be implemented continuously and use of alternative fuels should be encouraged to replace coal consumption. Clinker substitution by $\mathrm{BFS}$, fly ash and limestone generates considerable economic benefits. CCS could become a very important technology in the cement sector and its early commercial, large-scale application can reduce costs. It is concluded that energy efficiency improvements will continue to play the most important role in $\mathrm{CO}_{2}$ emission reduction and that clinker substitution should be implemented considering its low cost. CCS can contribute more significantly to $\mathrm{CO}_{2}$ reduction, but the higher costs incurred may delay its application.

\section{Acknowledgments}

Thanks to the supports from the Strategic Priority Research Program of the Chinese Academy of Sciences (No. XDB05050200), Science promotion programme of Research Centre for Ecoenvironmental Sciences, Chinese Academy of Sciences (YSW2013B05), the National Basic Research Program of China (No. 2010CB732300), the National High Technology Research and Development Program of China (No. 2012AA063101) and the China Scholarship Council.

\section{References}

2011a. Cement industry 12th Five-Year Development Plan.

2011b. China's Policies and Actions for Addressing Climate Change.

Abdelaziz, E.A., Saidur, R., Mekhilef, S., 2011. A review on energy saving strategies in industrial sector. Renewable and Sustainable Energy Reviews 15, 150-168.

Barker, D.J., Turner, S.A., Napier-Moore, P.A., Clark, M., Davison, J.E., 2009. $\mathrm{CO}_{2}$ capture in the cement industry. Energy Procedia 1, 87-94.

China Coal Resource, 2012. China coal resources by coal prices.

CSI/ECRA, 2008. Development of state of the art-techniques in cement manufacturing, try to look ahead (CSI/ECRA-technology papers).

Dahowski, R.T., Davidson, C.L., Li, X.C., Wei, N., 2012. A $\$ 70 / \mathrm{tCO}_{2}$ greenhouse gas mitigation backstop for China's industrial and electric power sectors: Insights from a comprehensive CCS cost curve. International Journal of Greenhouse Gas Control 11, 73-85.

Element Energy, 2010. Limited Potential for the application of CCS to UK industry and natural gas power generation for Committee on Climate Change.

Worrell, Ernst, Galitsky, Christina, Price, Lynn, 2008. Energy Efficiency Improvement Opportunities for the Cement Industry.

European Cement Research Academy, 2009. Technical report, ECRA CCS project.

Greenpeace Energy revolution, 2007. A sustainable China energy outlook.

Gu, A., Shi, X., Wang, L., Zhao, X., 2012. The potential and cost analysis of energy saving and emission reduction in china dement sector. China Population Resources and Environment 22, 16-21.

Hasanbeigi, A., Menke, C., Price, L., 2010a. The $\mathrm{CO}_{2}$ abatement cost curve for the Thailand cement industry. Journal of Cleaner Production 18, 1509-1518.

Hasanbeigi, A., Price, L., Lu, H., Lan, W., 2010b. Analysis of energy-efficiency opportunities for the cement industry in Shandong Province, China: a case study of 16 cement plants. Energy 35, 3461-3473.

He, H., 2009. Carbon dioxide emission in cement production and quantitive research. Cement Engineering, 61-65.

Hegerland, G.e.a., 2006. Capture of $\mathrm{CO}_{2}$ from a Cement Plant-Technical Possibilities and Economic Estimates in Greenhouse Gas Control Technologies.

IEA GHG, 2008. $\mathrm{CO}_{2}$ capture in the cement industry.

Jiang, K., 2011. Potential Secure Low Carbon Growth Pathways for the Chinese Economy.

Jiang, K., Hu, X., 2006. Energy demand and emissions in 2030 in China: scenarios and policy options. Environmental Economics and Policy Studies, 233-250.

Ke, J., Zheng, N., Fridley, D., Price, L., Zhou, N., 2012. Potential energy savings and $\mathrm{CO}_{2}$ emissions reduction of China's cement industry. Energy Policy 45, 739-751.

Lei, Y., Zhang, Q., Nielsen, C., He, K., 2011. An inventory of primary air pollutants and $\mathrm{CO}_{2}$ emissions from cement production in China, 1990-2020. Atmospheric Environment 45, 147-154

Liang, X., Li, J., 2012. Assessing the value of retrofitting cement plants for carbon capture: a case study of a cement plant in Guangdong, China. Energy Conversion and Management 64, 454-465.

Madlool, N.A., Saidur, R., Hossain, M.S., Rahim, N.A., 2011. A critical review on energy use and savings in the cement industries. Renewable and Sustainable Energy Reviews 15, 2042-2060.

Mahasenan, N., Dahowski, R.T., Davidson, C.L., 2005. The role of carbon dioxide capture and storage in reducing emissions from cement plants in North America. In: Rubin, E.S., Keith, D.W., Gilboy, C.F., Wilson, M., Morris, T., Gale, J., Thambimuthu, K. (Eds.), Greenhouse Gas Control Technologies 7. Elsevier Science Ltd, Oxford, pp. 901-909.

Marien, M., 2002. Futures studies in the 21st Century: a reality-based view. Futures $34,261-281$.

McKinsey, Company, 2009. Pathways to a Low-Carbon Economy, Version 2 of the Global Greenhouse Gas. Abatement Cost Curve

Moya, J.A., Pardo, N., Mercier, A., 2011. The potential for improvements in energy efficiency and $\mathrm{CO}_{2}$ emissions in the EU27 cement industry and the relationship with the capital budgeting decision criteria. Journal of Cleaner Production 19, 1207-1215.

Murray, A., Price, L., 2008. Use of Alternative Fuels in Cement Manufacture: Analysis of Fuel Characteristics and Feasibility for Use in the Chinese Cement Sector.

OECD/IEA, 2008. $\mathrm{CO}_{2}$ Capture and Storage: A Key Carbon Abatement Option.

OECD/IEA, WBCSD, 2009. Cement Technology Roadmap 2009, Carbon emissions reductions up to 2050 .

Pardo, N., Moya, J.A., Mercier, A., 2011. Prospective on the energy efficiency and $\mathrm{CO}_{2}$ emissions in the EU cement industry. Energy 36, 3244-3254

Price, L., Hasanbeigi, A., Lu, H., Wang, L., 2009. Analysis of Energy-Efficiency Opportunities for the Cement Industry in Shandong Province, China. 
Quantitative Economics and Audit Society of China, 2011. Cement Industry Structure Adjustment and Energy Consumption in the "Eleventh Five-Year Plan Period. China Cement 1, 30-35.

Shi, W., 2011. Some Issues on the Technology Roadmap for Low Carbon Development of China's Cement Industry. China Information Institute.

Shi, Y., Chen, L., Liu, Z., Yan, J., Hu, J., 2012. Analysis on the carbon emission reduction potential in the cement industry in terms of technology diffusion and structura adjustment: a case study of Chongqing. Energy Procedia 16, 121-130, Part A.

Singh, B., Strømman, A.H., Hertwich, E., 2011. Life cycle assessment of natural gas combined cycle power plant with post-combustion carbon capture, transport and storage. International Journal of Greenhouse Gas Control 5, 457-466.

Strategic Energy Technologies Information System, 2011. Energy efficiency and $\mathrm{CO}_{2}$ emission reduction in industry.

Tong, H., Cui, Y., Qu, W., Liu, Y., 2010. System dynamic scenarios analysis of $\mathrm{CO}_{2}$ emissions of China's cement industry. China Soft Science, 40-50.

Tsinghua University of China, 2008. Assisting Developing Country Climate Negotiators through Analysis and Dialogue: Report of Energy Saving and $\mathrm{CO}_{2}$ Emission Reduction Analysis in China Cement Industry.

United Nations, 2011. World Population Prospects: The 2010 Revision.

US EPA, 2010. Available and emerging technolgies for reducing greenhouse gas emissions from the portland cement industry.

VDZ Research Institute of the Cement Industry and PENTA Engineering Corp, 2008. Carbon Dioxide Control Technology Review.
Wang, F., Zhang, S., 2011. Forecasting long-run coal price in China: based on the state space mode. Statistics and Information Forum 26, 67-72.

WBCSD, 2009. The Cement Sustainability Initiative, Cement Industry Energy and $\mathrm{CO}_{2}$ Performance Getting the Numbers Right.

Worrel, E., Galitsky, C., 2008. Energy Efficiency Improvement and Cost Saving Opportunities for Cement Making, An Energy Star Guide for Energy and Plant Managers.

Wuppertal, 2012. CCS Global Prospects of Carbon Capture and Storage Technologies (CCS) in Emerging Economies Final Report to the German Federal Ministry for the Environment, Nature Conservation and Nuclear Safety (BMU) Part III: Country Study China. Wuppertal Institute.

WWF, 2008. A blueprint for a climate friendly cement industry.

$\mathrm{Xu}$, J.-H., Fleiter, T., Eichhammer, W., Fan, Y., 2012. Energy consumption and $\mathrm{CO}_{2}$ emissions in China's cement industry: a perspective from LMDI decomposition analysis. Energy Policy.

Zeman, F., Lackner, K., 2008. The Reduced Emission Oxygen Kiln, A White Paper Report for the Cement Sustainability Initiative of the World Business Council on Sustainable Development. Columbia University in New York.

Zeng, X., 2008. The status quo and energy efficiency improvements in Chinese cement sector.

Zeng, X., 2011. The cement industry,as a good example of a low carbon sector. 